\title{
A Study on Low-Cost Sensorless Drive of Brushless DC Motor for Compressor Using Random PWM
}

\author{
Duck-Shick Shin* and Dae-kyong Kim**
}

\begin{abstract}
Recently, it is increased to apply sensorless drive for BLDC (Brushless DC) motor to household electrical appliances, especially in the refrigerators and air conditioners, to reduce the cost and the acoustic noise by the operation and to make their functions more comfortable for human beings. In this paper, low-cost sensorless drive for BLDC motor is implemented by random PWM (Pulse Width Modulation). The experimental results show that the electromagnetic noise was reduced and the sound quality was improved by BLDC motor sensorless random PWM Control.
\end{abstract}

Keywords: BLDC, Random PWM, Sensorless

\section{Introduction}

The BLDC motor hold high efficiency over entire operating range and are easily controlled because the torque of the motor is proportional to input voltage. For the reasons, the BLDC motor is expanding the electrical appliances, especially in the refrigerators and air conditioners [1]. Recently, according to the increase of the concern for the improvement of home environment, many studies are attempted to reduce the vibration and noise developed from the sensorless BLDC drive for compressor [2-4].

The sources of the acoustic noise in the refrigerators are the compressor and the airflow fans for the condenser and evaporator, but the noise generated by the compressor is dominant [2]. The noise of compressor can be classified into two major parts: one is the electromagnetic noise of the motor and another is the mechanical noise caused by the mechanical components of the compressor such as the suction and discharge valves, muffler, and friction between the piston and cylinder, etc.

In addition, determination of PWM frequency ranges is important to select the modulating frequency ranges in the random PWM [4-8]. The harmonic currents and voltages will be spread over more broad range as the frequency ranges of the random PWM becomes broad. But the maximum available frequency ranges is limited by its operating characteristics, such as the natural resonance

\footnotetext{
* Korea Electronics Technology Institute (KETI), Korea (dsshin@keti.re.kr)

** Corresponding Author: Dept. of Electrical Control Engineering,

Sunchon National University, Korea. (dkkim@sunchon.ac.kr)

Received 17 January 2013; Accepted 08 February 2013
}

characteristics of the compressors, time limitation for the hardware and software for the motor control, and so on.

Considering the limited frequency ranges and cost, the low-cost motor drive for compressor is used low-cost microcontroller and the typical $5 \mathrm{kHz}$ switching frequency power module. In addition to reduce the electromagnetic noise of sensorless BLDC motor drive due to fixed switching PWM, random switching PWM is required.

This paper proposes a low-cost sensorless drive of BLDC motor for compressor using random PWM. It was verified that applying random PWM has reduced the electromagnetic noise and improved the sound quality.

\section{Sensorless Control of BLDC Motor}

The back-EMF's ea, eb and ec of BLDC motor have trapezoidal shapes and the currents ia, ib and ic needed to produce a steady state torque without torque pulsations are shown in Fig. 1.

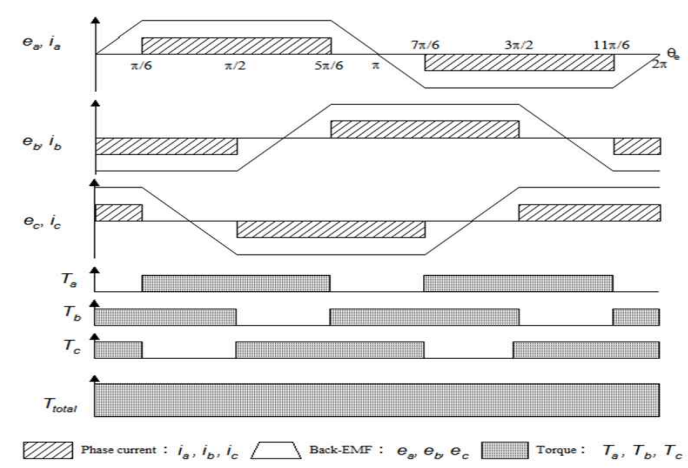

Fig. 1. Current, back-EMF and torque waveforms of BLDC motor 
In a position sensorless BLDC motor drive, commutation points of the inverter can be obtained by knowing the zerocross-point (ZCP) of the back-EMF and a speed dependent period of time delay [3-4]. The phase back-EMF induced in the stator windings of a BLDC motor is trapezoidal so that the ZCP of the back-EMF can be detected by monitoring the terminal voltage waveform of a silent phase. The instance when the terminal voltage of the silent phase match with the half DC link voltage, during which point switching devices are turned on, is the zero crossing point of the back-EMF.

The commutation points are estimated like this:

$$
\begin{gathered}
T_{c m t}(k)=T_{z c p}(k)+\frac{1}{2} \Delta T_{Z C P}(k) \\
\Delta T_{Z C P}(k)=T_{Z C P}(k)-T_{Z C P}(k-1)
\end{gathered}
$$

where, $\operatorname{Tcmt}(\mathrm{k})$ is the commutation time and $\operatorname{TZCP}(\mathrm{k})$ is the zero crossing time of the back-EMF.

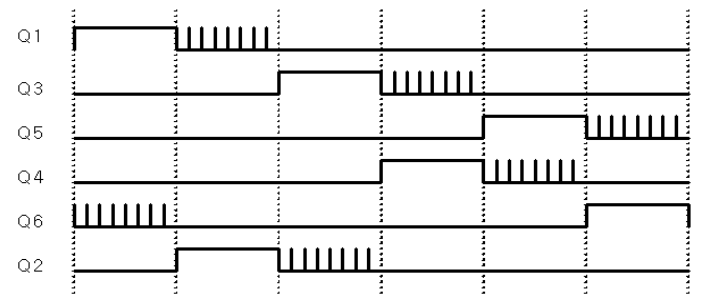

(a)

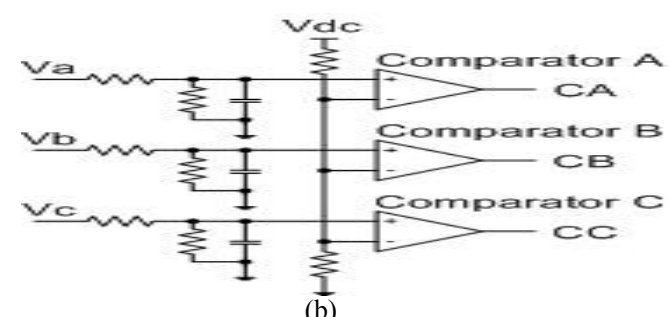

(b)

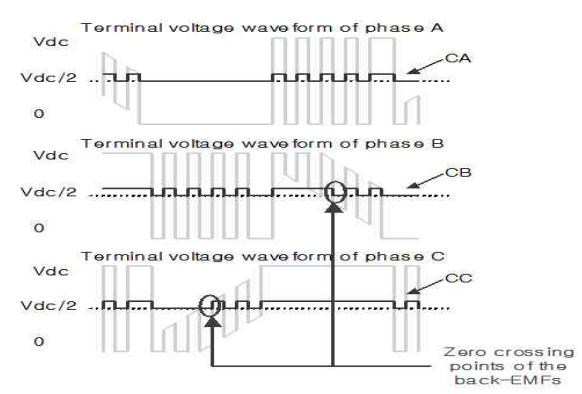

(c)

Fig. 2. (a) switching pattern, (b) terminal voltage sensing circuit and

(c) terminal voltage waveforms
Fig. 2 (a) the switching pattern of the out-going phase unipolar PWM, fig. 2 (b) the terminal voltage sensing circuit, and fig. 2 (c) the motor terminal voltage waveforms when the out-going phase unipolar PWM is applied. The terminal voltage sensing circuit in fig. 2 (b) compares the terminal voltage of each phase with the half DC link voltage. In fig. 2 (b), capacitor $\mathrm{C}$ is used to reduce switching noises included in the terminal voltage.

The sensorless control method based on terminal voltage sensing cannot be used during low speeds since the back-EMF is zero at rest and proportional to the speed.

\section{Random PWM Algorithm}

The electromagnetic noise will be dominant at low speeds. Operating the BLDC motor at $1,600 \mathrm{rpm}$ can reduce the mechanical noise effectively, but the electromagnetic noise generated by PWM may influence considerably the total acoustic noise. The BLDC inverter refrigerator has to be mostly operated at low speed near 1,600rpm for power consumption, except for initial starting and overload conditions where the large cooling capacity is required. Therefore, reducing the electromagnetic noise and psychoacoustic noise of the compressor at low speed operation will be the most important factor to reduce the acoustic noise of the refrigerators [2].

Random PWM techniques [5] are investigated and these techniques include driving at a high switching frequency and to reduce the switching noise. Random PWM is classified into two categories as random switching frequency PWM and random pulse position PWM. Even though the random pulse position PWM [5-8] is operated at a fixed frequency, the random pulse position has a similar effect as if the switching frequency is changed. This method has merit that can be easily implemented by a micro controller.

The random numbers use carefully so as not to come overflow $i_{c}$ use prime number. $i_{c}$ and $i_{m}$ stand in the relation of (3)

$$
i_{c} \approx\left(\frac{1}{2}-\frac{1}{6} \sqrt{3}\right) i_{m}
$$

Table 1 shows constants for portable random number. the random number have to use constantly. In this paper using LCG (Linear Congruential Generator) random number of 220, 6075, 106, 1283. 
Table 1. Constants for portable random number

\begin{tabular}{|c|l|l|l|}
\hline $\begin{array}{c}\text { Overf } \\
\text { ow at }\end{array}$ & $i_{m}$ & $i_{a}$ & $i_{c}$ \\
\hline $2^{20}$ & 6075 & 106 & 1283 \\
\hline $2^{21}$ & 7875 & 211 & 1663 \\
\hline $2^{22}$ & 7875 & 421 & 1663 \\
\hline & 11979 & 430 & 2531 \\
$2^{23}$ & 6655 & 936 & 1399 \\
& 6075 & 1366 & 1283 \\
\hline & 53125 & 171 & 11213 \\
$2^{24}$ & 11979 & 859 & 2531 \\
& 14406 & 967 & 3041 \\
\hline
\end{tabular}

Fig. 3 (a) and fig. 3 (b) show the random distributions along with chosen coefficients. Fig. 3 (a) shows result by proper constants for portable random number. Multiplier is 6075 , increment is 106 , modulus is 1283 . The random number generate 500 times. It has a uniform distribution. Fig. 3 (b) shows result by improper constants for portable random number. Modulus use 1260 Instead of 1283. It has a multiform distribution.

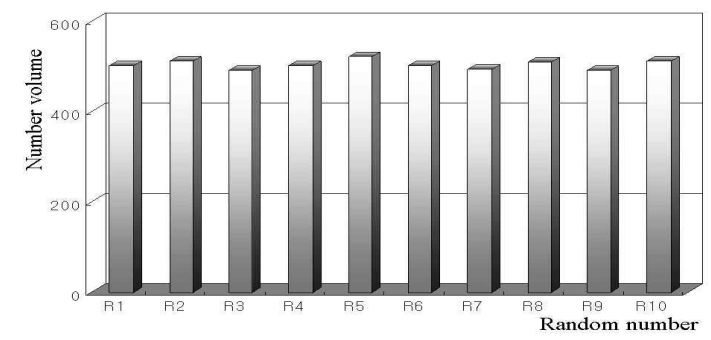

(a) Properly chosen coefficients $\left(\boldsymbol{i}_{\boldsymbol{m}}=6075, \boldsymbol{i}_{\boldsymbol{a}}=106, \boldsymbol{i}_{\boldsymbol{c}}=1283\right)$

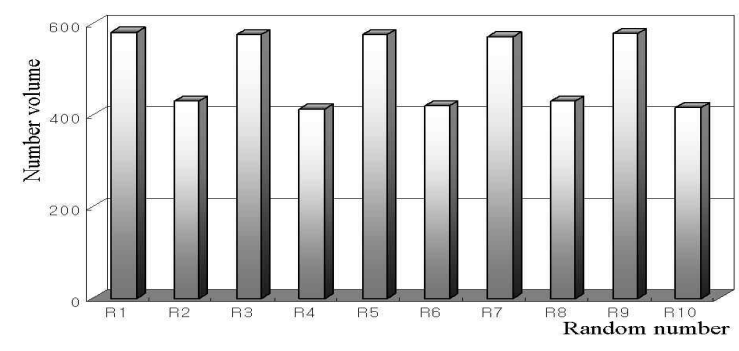

(b) Improperly chosen coefficients (im=6075, ia=106, $\mathrm{ic}=1260)$

Fig. 3. Random distributions along with chosen coefficients

In this paper, random number is generated by LCG(Linear Congruential Generator) like (4).

$$
f_{\text {ran+1 }}=\left(f_{\text {ran }} \times i_{a}+i_{c}\right) \% i_{m}
$$

Fig. 4 shows the block diagram of the speed control for the sensorless Drive for Brushless DC Motors using RPWM. The absolute rotor position for commutation was detected by using the back EMF voltages of the open phases. The brushless DC motor was initially positioned at a predetermined position and is forced to accelerate to the arbitrary speed where the rotor position can be detected from the back EMF voltages. The low-cost fixed-point digital signal processor (DSP), TMS320LF2406A and the typical $5 \mathrm{kHz}$ switching frequency SPM (Smart Power Module) of Fairchild-semiconductor implement the motor speed control algorithm, generation of the random number and determination of the switching frequency according to the random number, and also determines the switching states of the inverter corresponding to the required duty ratio. The random numbers were generated by using LCG random number of $220,6075,106,1283$.

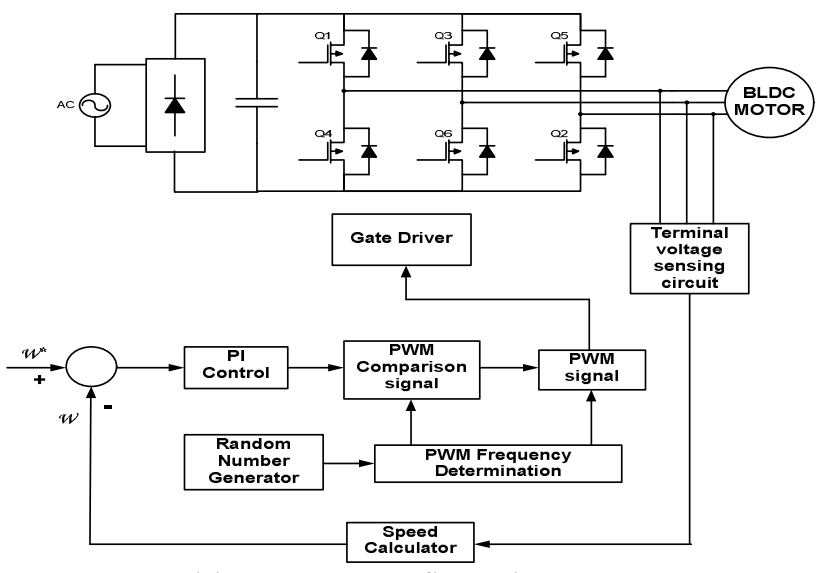

Fig. 4. Motor drive system configuration

Table 2. shows the electrical parameters of the used BLDC motor to examine the performance of the proposed method.

Table 2. Motor parameters

\begin{tabular}{|c|c|}
\hline Rated power & $200 \quad[\mathrm{w}]$ \\
\hline Number of pole & 4 \\
\hline Line to line resistance & $7.5 \quad[\Omega]$ \\
\hline Line to line inductance & $0.021 \quad[\mathrm{H}]$ \\
\hline Back-EMF constant & $57.78 \quad\left[V_{r m s} / \mathrm{krpm}\right]$ \\
\hline
\end{tabular}

where, $i_{a}$ is multiplier, $i_{c}$ is increment, $i_{m}$ is modulus. Also, random number is generated in the specific frequency range using (5).

$$
f=f_{\text {lower }}+\frac{\left(\left(f_{\text {upper }}-f_{\text {lower }}+1\right) \times f_{\text {ran }}\right)}{i_{m}}
$$

The lower and upper limit frequencies of the random 
PWM were determined by $3 \mathrm{kHz}$ and $5 \mathrm{kHz}$, respectively, by considering the mechanical resonance with PWM frequency, the minimum required time for hardware and algorithm processing, as well as the reliability including EMI and leakage currents.

\section{Simulation and Experimental Results}

Fig. 5 shows the PSIM simulation schematic. The schematic includes DLL of random PWM generation.

Fig. 6 shows the measured noise point of compressor. Fig. 7 (a) shows the phase current FFT (Fast Fourier Transform) for the deterministic PWM with $4 \mathrm{kHz}$ switching when the motor speeds is $1,600 \mathrm{rpm}$. The similar waveform for the random PWM is shown in Fig. 7 (b). Observing a part of $4 \mathrm{kHz}$ frequency, respectively reduce the deviation of the current.

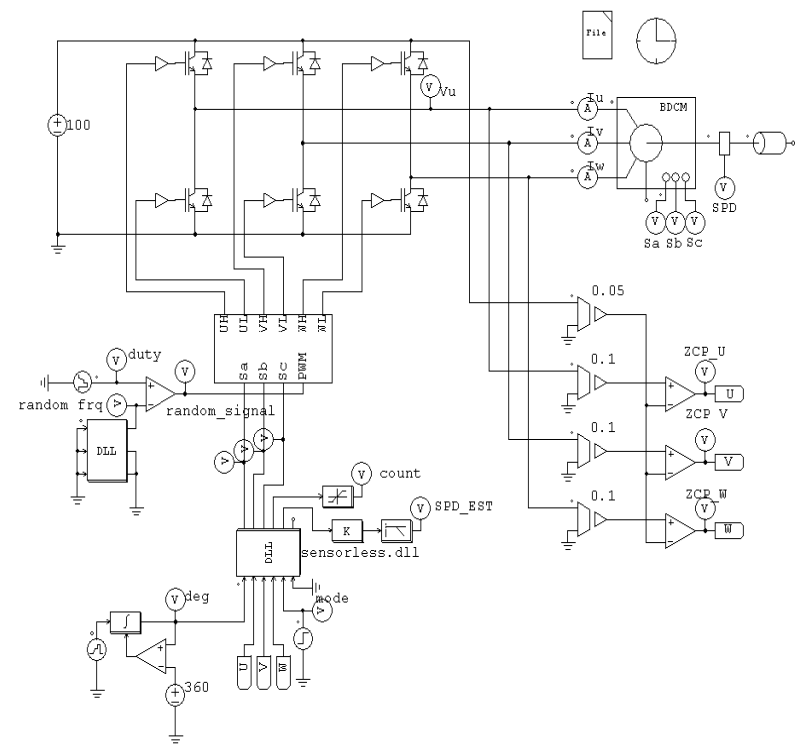

Fig. 5. PSIM simulation schematic

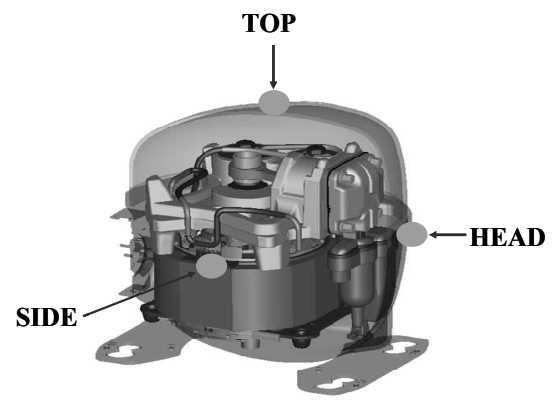

Fig. 6. Measured noise point of compressor

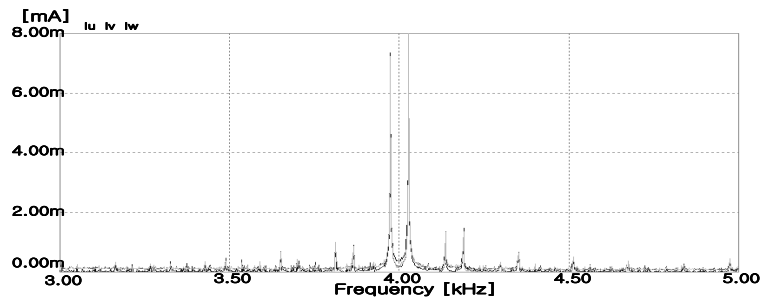

(a) fixed switching PWM

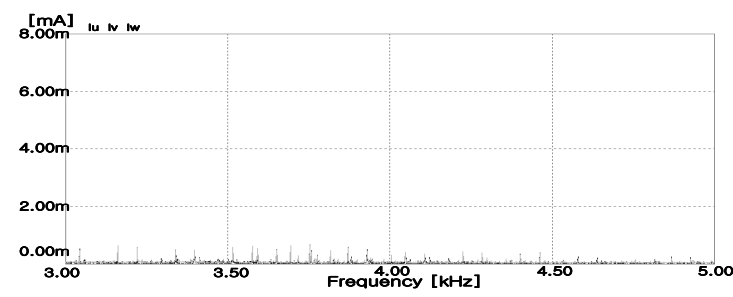

(b) random switching PWM

Fig. 7. phase current FFT

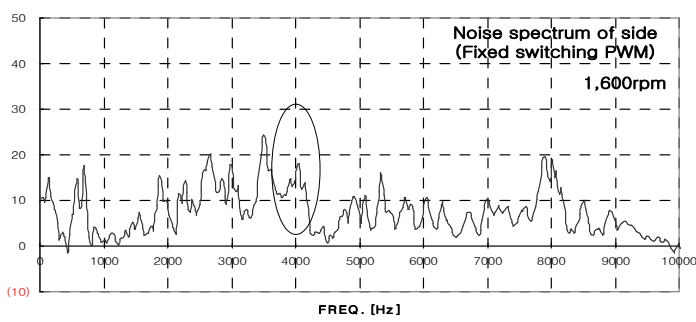

(a) noise spectrum of $\operatorname{side}(4 \mathrm{kHz})$

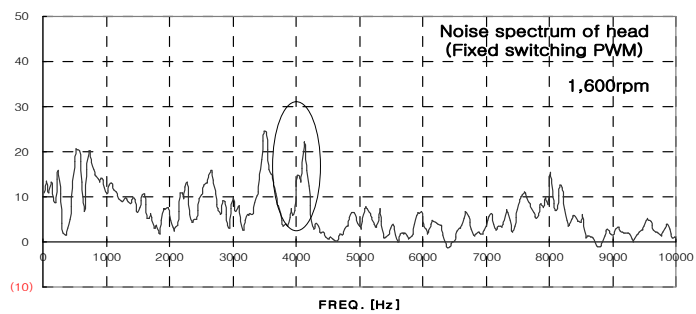

(b) noise spectrum of head $(4 \mathrm{kHz})$

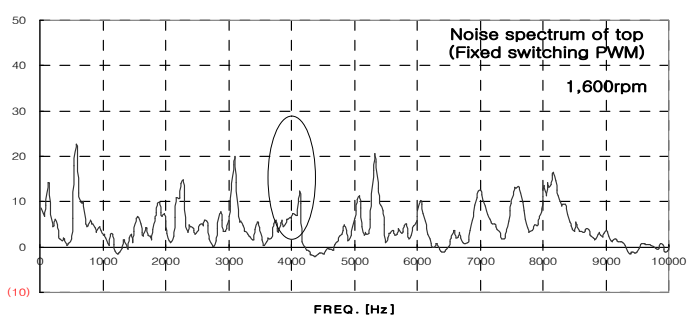

(c) noise spectrum of top $(4 \mathrm{kHz})$

Fig. 8. Fixed switching $\operatorname{PWM}(1,600 \mathrm{rpm})$ 
Fig. 8 and Fig. 9 show the noise spectrums measured from the side, head and top of compressor applied the fixed switching PWM with $4 \mathrm{kHz}$ and random switching PWM with $3 \sim 5 \mathrm{kHz}$ when the motor speeds is $1,600 \mathrm{rpm}$. Observing a part of $3 \sim 5 \mathrm{kHz}$ frequency precisely, the noise deviation of the compressor for the random switching PWM is much more reduced than the fixed switching PWM with $4 \mathrm{kHz}$.

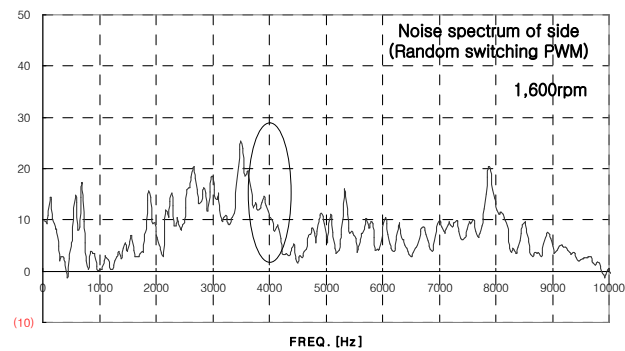

(a) noise spectrum of $\operatorname{side}(3 \sim 5 \mathrm{kHz})$

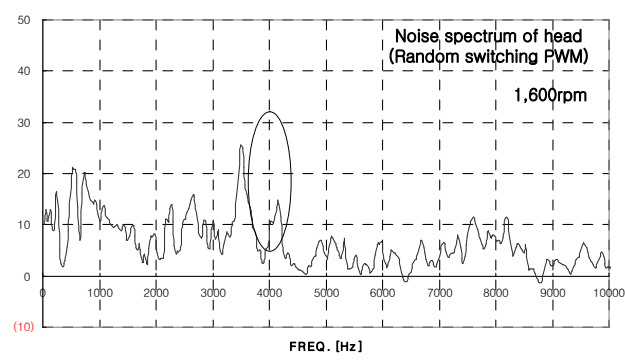

(b) noise spectrum of head $(3 \sim 5 \mathrm{kHz})$

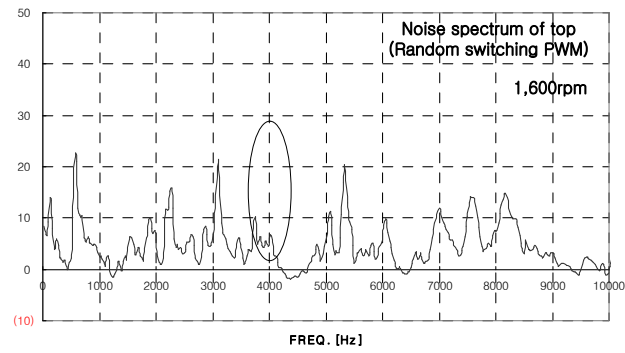

(c) noise spectrum of top $(3 \sim 5 \mathrm{kHz})$

Fig. 9. Random switching PWM(1,600rpm)

Fig. 10 and fig. 11 describe the noise spectrums measured from the side, head and top of compressor applied the fixed switching PWM with $4 \mathrm{kHz}$ and random switching PWM with $3 \sim 5 \mathrm{kHz}$ when the motor speeds is $2,000 \mathrm{rpm}$. Observing a part of $3 \sim 5 \mathrm{kHz}$ frequency precisely, the noise deviation of the compressor for the random switching PWM is much more reduced than the fixed switching PWM with $4 \mathrm{kHz}$. Therefore, it is noted that the random switching PWM control effectively suppresses reduction of the deviation of the electromagnetic noise and improves sound quality.

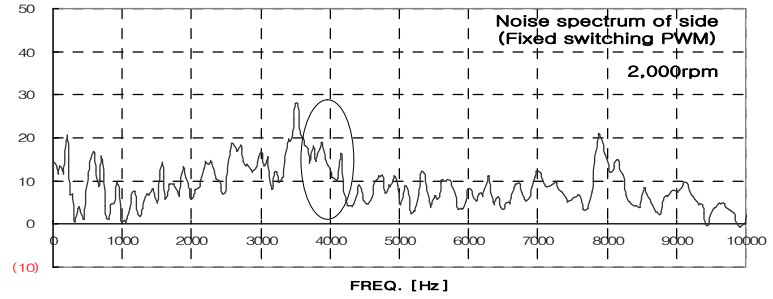

(a) noise spectrum of $\operatorname{side}(4 \mathrm{kHz})$

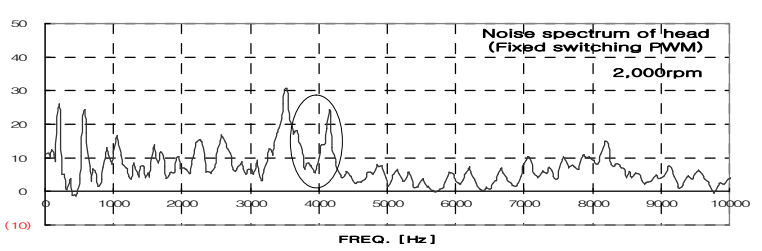

(b) noise spectrum of head $(4 \mathrm{kHz})$

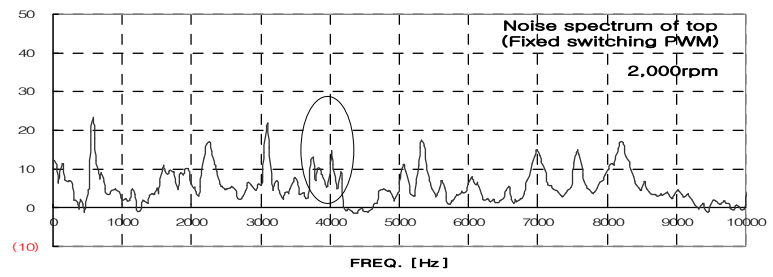

(c) noise spectrum of top $(4 \mathrm{kHz})$

Fig.10. Fixed switching PWM(2,000rpm)

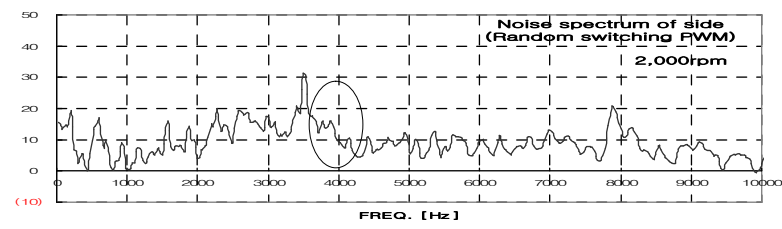

(a) noise spectrum of $\operatorname{side}(3 \sim 5 \mathrm{kHz})$

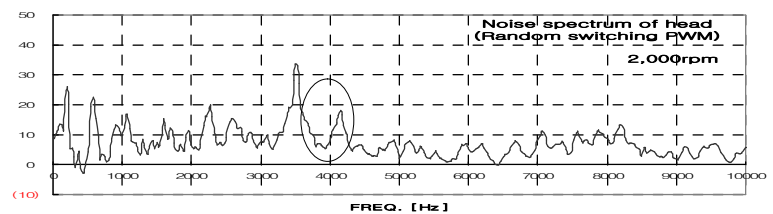

(b) noise spectrum of head $(3 \sim 5 \mathrm{kHz})$

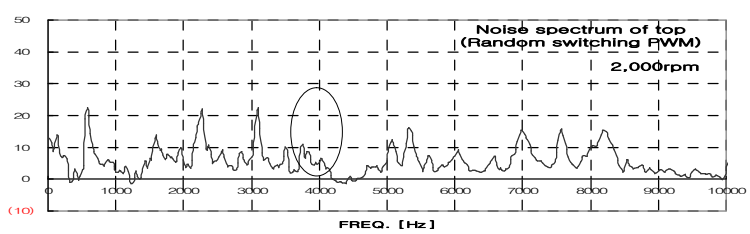

(c) noise spectrum of top $(3 \sim 5 \mathrm{kHz})$

Fig. 11. Random switching PWM(2,000rpm) 


\section{Conclusions}

In this paper, low-cost sensorless drive of brushless DC motor for compressor using random PWM is implemented by using low-cost fixed point DSP and typical $5 \mathrm{kHz}$ switching frequency power module. In low-cost inverter refrigerator with the reciprocating compressor driven by the BLDC motor, applying the random PWM reduces the electromagnetic noise and improves the sound quality. The proposed method makes possible low-cost home appliances using BLDC motor, such as refrigerator and air-conditioner, to obtain the good sound quality.

\section{Acknowledgements}

This work was supported by the New \& Renewable Energy of the Korea Institute of Energy Technology Evaluation and Planning (KETEP) grant funded by the Korea government Ministry of Knowledge Economy. (No. 20113030060010)

\section{References}

[1] Electric Power Research Institute, "Electric Motors; Markets, Trends, and Application," Tech. Rep. TR-100423, Jun. 1992.

[2] K Y Cho, S B Yang, H W Kim and J C Kim, "Improving Sound Quality of Reciprocating Compressor Using Random PWM" IEE Power Electronics and Variable Speed Drives, pp 431-436, Sep. 2000

[3] Dae-kyong Kim, Kwang-Woon Lee, Byung-Il Kwon, "Commutation Torque Ripple Reduction in a Position Sensorless Brushless DC Motor Drive," IEEE Trans. On Power Electronics, vol. 21, NO. 6, pp. 1762-1768, Nov. 2006

[4] Kwang-woon Lee, Dae-kyong Kim, Byung-Taek Kim, Byung-il Kwon, "A Novel Starting Method of the SPM-type BLDC Motors without Position Sensor for Reciprocating Compressor", IEEE Transactions On Industry Applications, Vol. 44, No. 1, January/February 2008

[5] M. M. Bech, J. K. Pedersen and F. Blaabjerg, "Random Modulation Techniques Width Fixed Switching Frequency for Three-Phase Power Converters", IEEE Trans. Power Electron., vol.15, no.4, pp.753-761, 2000.

[6] Y.G. Jung, S.H. Na, Y.C. Lim and H.G. Kim, "Implementation of a DSP Controlled Random Switching Frequency PWM Inverter for Industrial Drives", in Proc. ICEE(Korea),2002,pp.575-580.

[7] M.M. Bech, J.K. Pedersen, and F. Blaabjerg, "Field-oriented Control of an Induction Motor Using Random Pulse Width Modulation", in Proc. IEEE APEC '00, 2000, pp. 924 931.

[8] S.O. Wi, Y.G. Jung, and Y.C. Lim "Power Spectrum of TwoPhase and Three-Phase RCD-PWM Scheme for Switching Noise Reduction of Induction Motors", KIPE Transaction, vol.9, no.2, pp.180-188, 2004.

[9] S.O. Wi, Y.G. Jung, S.H. Na and Y.C. Lim, "Separately Randomized Pulse Position PWM Technique with Fixed Switching Frequency for Power Electronics Converters", in Proc. ICEE(Korea),2002,pp.780-781.

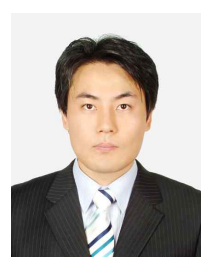

Duck-Shick Shin received a B.S. degree in electrical engineering from Honam University, Gwangju, Korea, in 2004 and, a M.S degree from Chonnam National University, Gwangju, Korea, in 2006. He is currently a Senior-Researcher at the Korea Electronics Technology Institute. His research interests included power electronics and motor control and design.

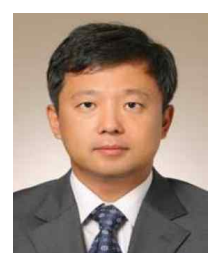

Dae-kyong Kim received his M.S. degree in Electrical Engineering and his Ph.D. degree in the Department of Electronic, Electrical, Control and Instrumentation Engineering from Hanyang University, Korea in 2001 and 2007, respectively. From 2001 to 2005, he was a Senior Engineer in the Home Appliances R\&D Center where he was engaged in research and development of sensorless motor drive systems for refrigerator and air-conditioner at the Samsung Electronics, Korea. From 2005 to 2011, he was a Center Director of Digital Convergence Center at the Korea Electronics Technology Institute (KETI). Since 2011, he has been with the Department of Electrical Control Engineering, Sunchon National University, Korea as an assistant professor. His current research is in analysis, design, and drives of electrical machines for energy saving and high-performance. He received several Best Paper Awards from the Korea Institute of Electrical Engineers (KIEE), ICEMS2007 and IEEE INTELEC2009. He received a R\&D award from Samsung Electronics, a staff award from Korea Electronics Technology Institute (KETI) and a mayor award from Gwangju-city, Korea. He served as Co-chairs and secretary for IEEE INTELEC2009, ICEMS2010, IEEE VPPC2012, and CEFC2012, and other domestic and international conference. 